\title{
Interaction Effects of Arbuscular Mycorrhizal Fungi and Different Phosphate Levels on Growth Performance of Catharanthus roseus Linn.
}

\author{
Mohd AYOOB*, Irfan AZIZ, Paramjit KaurJITE \\ University of Pune, Department of Botany, Pune, 411007, India; ayoubuni@gmail.com ("corresponding author)
}

\begin{abstract}
Catharanthus roseus L. (Apocynaceae), a valuable medicinal plant with potential therapeutic value was inoculated with AM fungi Glomus fasciculatum under three different phosphate conditions. Catharanthus roseus plants raised in presence of the AM fungi showed increased growth in terms of (shoot length, root length, leaf number, fresh weight and dry weight). Total chlorophyll content and phosphate content of the shoot was found to be significantly higher in AM inoculated plants as compared to non AM Catharanthus plants. The activities of phosphatase enzymes were found to be increased in AM inoculated plants as compared to non AM plants. Root colonization percent was significantly higher in AM inoculated plants at zero and at all three phosphate levels after 60,90 and 120 days of AM inoculation, but decreased at third phosphate level after 120 days of AM inoculation. The study suggests that Catharanthus roseus is dependent on the mycorrhizal fungi to a large extent for its growth and survival and also shows the potential of AM fungi Glomus fasciculatum in increasing growth and biomass of Catharanthus roseus $\mathrm{L}$.
\end{abstract}

Keywords: AM fungi, Catharanthus roseus, Glomus fasciculatum, phosphatase enzymes

\section{Introduction}

Catharanthus roseus (L.) G. Don (Madagascar periwinkle) belonging to the family Apocynaceae is an important and highly exploited medicinal plant from which secondary metabolites used in chemotherapy to treat diverse cancers are extracted. The leaves and stem are the sources of natural dimeric alkaloids vinblastine and vincristine that are essential parts of most anticancer chemotherapies (Van der Heijden et al., 2004). Large scale mass production of this important medicinal plant requires commercial cultivation especially in areas that are not suitable for traditional farming systems.

Plant roots interact with a wide variety of microorganisms in the soil, among these arbuscular mycorrhizal fungi form an important component of soil microflora. Root colonization by arbuscular mycorrhizal (AM) fungi has been shown to increase the productivity of several crops, especially important in the context of sustainable agriculture and development (Smith and Read, 1997; Podeszfinski et al., 2002). In recent years, due to over exploitation of natural resources, biofertilizers have emerged as important components of integrated nutrient supply system and hold a promise for reducing the production costs, improving the crop yields, quality, nutrientsupplies and sustaining the productivity over a longer period (Gill et al., 2002). Beneficial effects of AM symbiosis on plant growth, nutrient uptake, and tolerance to environmental stressors have been extensively reported (Koide and Mosse, 2004; Audet and Charest, 2007). However, these fungi show a preferential colonization to hosts and thus the extent to which the host benefit depends of the fungal species involved in the symbiosis (Miller et al., 1987).

The selection of efficient AM fungi is a key prerequisite for inoculation programs since there are different levels of compatibility between host plants and AM fungi (Smith and Read, 1997). The present pot culture study was undertaken to understand the physiological and biochemical response of Catharanthus roseus to one of the most efficient AM fungus Glomus fasciculatum at three different phosphate levels.

\section{Materials and methods}

The seeds of Catharanthus roseus were obtained from Government Nursery, University of Pune, Maharashtra India. The experiment was conducted in open natural conditions in Botanical Garden, Department of Botany, University of Pune.

Fifty days old seedlings with uniform height were used in the experiment. Three month old $30 \mathrm{~g}$ of mycorrhizal inoculum of Glomus fasciculatum (Thaxter) Gerd. and Trappe emend. Walker and Koske containing AM colonized roots, rhizosphere soil having extramatrical mycelium and spores (10-15 spores/g of soil) were used as a source of inoculum for each seedling. The inoculum was directly attached to the roots of the seedlings. The experiment consists of eight treatments, nine replicates of each treatment were grown, a total of 72 pots were arranged in completely randomized block design. The treatments consisted of: non AM control, i.e. zero phosphate level and three different phosphate levels of $50 \mathrm{mg}, 100 \mathrm{mg}$ 
76

and $150 \mathrm{mg}$ respectively and AM inoculated plants with zero phosphate level and three different phosphate levels respectively. Four seedlings were maintained in each polyethylene bag having a size of $12 \times 14^{\prime \prime}$ containing eight $\mathrm{kg}$ of autoclaved soil (autoclaved for one hour at $121^{\circ} \mathrm{C}$ ) and the seedlings were watered daily according to their needs. $\mathrm{K}_{2} \mathrm{HPO}_{4}$, dipotassium phosphate (analytical reagent) was used as a source of phosphate. Phosphate treatment was given after 30 days of AM inoculation and after that phosphate was given weekly until the last observation was recorded. Observations were recorded after 60, 90, and 120 days after AM inoculation.

\section{Growth measurement}

Plants were harvested after 60,90 and 120 days of AM inoculation and were then analyzed for morphological parameters such as shoot length, root length, leaf number, fresh weight and dry weight.

\section{AM colonization}

The percentage of AM colonization in roots was analyzed by clearing and staining of roots by the method of Phillips and Hayman (1970) and percent AM colonization in root was determined by gridline intersect method Giovannetti and Mosse (1980).

\section{Physiological and biochemical parameters}

Leaf chlorophyll content was determined by the method of Arnon (1949). The amount of total chloro- phyll was expressed in $\mathrm{mg} / \mathrm{g}$ fresh weight. Total $\mathrm{P}$ content was measured as described by Fiske and Subbarao (1925) method. Amount of phosphorus was expressed in $\mathrm{mg} / \mathrm{g}$ dry weight.

Acid and alkaline phosphatase activity was measured by the method of Lowry et al. (1954).

Absorbance was read at $405 \mathrm{~nm}$. The amount of phosphatase activity was expressed in moles of para-nitro phenol (PNP) released/minutes/g of fresh weight of roots.

Statistical analysis was done with the help of statistical package for social sciences (SPSS) software followed by Duncan's Multiple Range Test (DMRT) and different small alphabetical letters indicate significant differences at $\mathrm{p} \leq 0.05$ level.

\section{Results and discussion}

In the present investigation AM fungi (Glomus fasciculatum) was found to have a significant effect on the growth and development of Catharanthus roseus. The difference between the mycorrhizal and non mycorrhizal Catharanthus plants was visible just after 20 days of AM inoculation, before phosphate was being applied. AM inoculated plants flowered two weeks before the control and produced more flowers at the first flush. As shown in Tab. 1, significant increase was observed in various morphological parameters like shoot length, root length and leaf number in Glomus fasciculatum inoculated Catharanthus plants after 60, 90 and 120 days as compared to non

Tab. 1. Morphological parameters of Catharanthus roseus L. after 60, 90 and 120 days of AM inoculation under three different phosphate conditions

\begin{tabular}{ccccccc}
\hline \multirow{2}{*}{ Treatments } & \multicolumn{3}{c}{ Shoot length $(\mathrm{cm})$} & \multicolumn{3}{c}{ Root length $(\mathrm{cm})$} \\
\cline { 2 - 7 } & 60 days & 90 days & 120 days & 60 days & 90 days & 120 days \\
\hline C & $8.33 \pm 1.53 \mathrm{f}$ & $12.00 \pm 1.00 \mathrm{f}$ & $13.00 \pm 1.00 \mathrm{f}$ & $7.67 \pm 1.53 \mathrm{e}$ & $12.67 \pm 1.15 \mathrm{~d}$ & $13.00 \pm 1.00 \mathrm{c}$ \\
C+1P & $10.00 \pm 2.00 \mathrm{ef}$ & $14.00 \pm 1.00 \mathrm{ef}$ & $16.00 \pm 1.00 \mathrm{e}$ & $10.00 \pm 1.00 \mathrm{de}$ & $21.00 \pm 2.00 \mathrm{c}$ & $24.33 \pm 2.08 \mathrm{c}$ \\
C+2P & $13.33 \pm 1.53 \mathrm{~d}$ & $16.33 \pm 1.53 \mathrm{e}$ & $21.00 \pm 1.00 \mathrm{~d}$ & $12.00 \pm 1.00 \mathrm{de}$ & $23.67 \pm 1.53 \mathrm{c}$ & $27.00 \pm 2.00 \mathrm{c}$ \\
C+3P & $16.67 \pm 1.53 \mathrm{~d}$ & $25.00 \pm 1.00 \mathrm{~d}$ & $31.00 \pm 1.00 \mathrm{c}$ & $14.00 \pm 4.00 \mathrm{~d}$ & $32.00 \pm 3.61 \mathrm{~b}$ & $38.00 \pm 2.00 \mathrm{~b}$ \\
\hline Gf & $24.00 \pm 2.00 \mathrm{c}$ & $33.00 \pm 2.65 \mathrm{c}$ & $36.67 \pm 1.53 \mathrm{~b}$ & $23.67 \pm 4.04 \mathrm{c}$ & $34.00 \pm 5.29 \mathrm{~b}$ & $39.33 \pm 2.52 \mathrm{~b}$ \\
Gf $+1 \mathrm{p}$ & $28.00 \pm 2.00 \mathrm{~b}$ & $38.00 \pm 2.00 \mathrm{~b}$ & $40.33 \pm 2.52 \mathrm{a}$ & $28.67 \pm 3.21 \mathrm{bc}$ & $41.00 \pm 2.00 \mathrm{a}$ & $45.33 \pm 1.53 \mathrm{a}$ \\
Gf+2p & $33.67 \pm 2.52 \mathrm{a}$ & $41.00 \pm 1.00 \mathrm{a}$ & $43.00 \pm 1.00 \mathrm{a}$ & $33.67 \pm 3.06 \mathrm{ab}$ & $43.33 \pm 2.08 \mathrm{a}$ & $46.33 \pm 1.53 \mathrm{a}$ \\
Gf $+3 \mathrm{p}$ & $36.67 \pm 3.51 \mathrm{a}$ & $42.33 \pm 1.53 \mathrm{a}$ & $43.00 \pm 2.00 \mathrm{a}$ & $37.67 \pm 4.51 \mathrm{a}$ & $45.67 \pm 1.53 \mathrm{a}$ & $47.67 \pm 3.06 \mathrm{a}$ \\
\hline
\end{tabular}

Tab. 2. Fresh weight and dry weight of Catharanthus roseus L. after 60, 90 and 120 days of AM inoculation under three different phosphate conditions

\begin{tabular}{ccccccc}
\hline \multirow{2}{*}{ Treatments } & \multicolumn{3}{c}{ Fresh weight $(\mathrm{g})$} & \multicolumn{3}{c}{ Dry weight $(\mathrm{g})$} \\
\cline { 2 - 7 } & 60 days & 90 days & 120 days & 60 days & 90 days & 120 days \\
\hline C & $0.98 \pm 0.23 \mathrm{~d}$ & $1.82 \pm 0.16 \mathrm{~h}$ & $2.05 \pm 0.43 \mathrm{e}$ & $0.24 \pm 0.06 \mathrm{~g}$ & $0.42 \pm 0.05 \mathrm{~g}$ & $0.67 \pm 0.08 \mathrm{~g}$ \\
$\mathrm{C}+1 \mathrm{P}$ & $1.87 \pm 0.67 \mathrm{~d}$ & $2.74 \pm 0.16 \mathrm{~g}$ & $3.02 \pm 0.32 \mathrm{e}$ & $0.37 \pm 0.07 \mathrm{~g}$ & $0.59 \pm 0.03 \mathrm{f}$ & $0.89 \pm 0.15 \mathrm{f}$ \\
$\mathrm{C}+2 \mathrm{P}$ & $2.33 \pm 0.28 \mathrm{~d}$ & $4.22 \pm 0.23 \mathrm{f}$ & $5.71 \pm 0.78 \mathrm{~d}$ & $0.54 \pm 0.10 \mathrm{f}$ & $1.25 \pm 0.11 \mathrm{e}$ & $1.48 \pm 0.07 \mathrm{e}$ \\
$\mathrm{C}+3 \mathrm{P}$ & $4.17 \pm 0.66 \mathrm{c}$ & $8.22 \pm 0.16 \mathrm{e}$ & $9.24 \pm 1.16 \mathrm{c}$ & $0.74 \pm 0.07 \mathrm{e}$ & $1.54 \pm 0.09 \mathrm{~d}$ & $2.48 \pm 0.17 \mathrm{~d}$ \\
\hline Gf & $7.85 \pm 0.96 \mathrm{~b}$ & $10.26 \pm 0.12 \mathrm{~d}$ & $11.84 \pm 1.06 \mathrm{~b}$ & $1.82 \pm 0.08 \mathrm{~d}$ & $2.73 \pm 0.06 \mathrm{c}$ & $3.13 \pm 0.06 \mathrm{c}$ \\
Gf $+1 \mathrm{p}$ & $8.04 \pm 1.22 \mathrm{~b}$ & $11.46 \pm 0.11 \mathrm{c}$ & $2.98 \pm 0.57 \mathrm{~b}$ & $2.07 \pm 0.13 \mathrm{c}$ & $3.11 \pm 0.08 \mathrm{~b}$ & $3.54 \pm 0.08 \mathrm{~b}$ \\
Gf $+2 \mathrm{p}$ & $10.01 \pm 0.32 \mathrm{a}$ & $11.99 \pm 0.17 \mathrm{~b}$ & $14.59 \pm 0.59 \mathrm{a}$ & $2.16 \pm 0.09 \mathrm{~b}$ & $3.24 \pm 0.10 \mathrm{ab}$ & $3.95 \pm 0.09 \mathrm{a}$ \\
Gf $+3 \mathrm{p}$ & $11.20 \pm 1.08 \mathrm{a}$ & $12.83 \pm 0.16 \mathrm{a}$ & $15.51 \pm 1.22 \mathrm{a}$ & $2.33 \pm 0.11 \mathrm{a}$ & $3.33 \pm 0.07 \mathrm{a}$ & $3.98 \pm 0.15 \mathrm{a}$ \\
\hline
\end{tabular}


Tab. 3. Acid and alkaline phosphatase activity in Catharanthus roseus L. after 60, 90 and 120 days of AM inoculation under three different phosphate conditions

\begin{tabular}{ccccccc}
\hline \multirow{2}{*}{ Treatments } & \multicolumn{3}{c}{$\begin{array}{c}\text { Acid phosphatase activity } \mu \text { mole } \\
\text { pnp-released/g fresh weight }\end{array}$} & \multicolumn{2}{c}{$\begin{array}{c}\text { Alkaline phosphatase activity } \mu \text { mole } \\
\text { pnp-released/g fresh weight }\end{array}$} \\
\cline { 2 - 4 } & 60 days & 90 days & 120 days & 60 days & 90 days & 120 days \\
\hline C & $0.422 \pm 0.027 \mathrm{f}$ & $0.713 \pm 0.025 \mathrm{f}$ & $0.790 \pm 0.033 \mathrm{e}$ & $0.767 \pm 0.056 \mathrm{f}$ & $0.931 \pm 0.036 \mathrm{f}$ & $1.098 \pm 0.072 \mathrm{f}$ \\
$1 \mathrm{P}$ & $0.514 \pm 0.049 \mathrm{e}$ & $0.834 \pm 0.019 \mathrm{e}$ & $0.929 \pm 0.014 \mathrm{~d}$ & $0.811 \pm 0.049 \mathrm{de}$ & $1.034 \pm 0.032 \mathrm{e}$ & $1.179 \pm 0.035 \mathrm{ef}$ \\
2P & $0.649 \pm 0.032 \mathrm{~d}$ & $0.989 \pm 0.024 \mathrm{~d}$ & $1.141 \pm 0.025 \mathrm{c}$ & $0.913 \pm 0.030 \mathrm{~d}$ & $1.122 \pm 0.073 \mathrm{e}$ & $1.257 \pm 0.057 \mathrm{de}$ \\
3P & $0.691 \pm 0.030 \mathrm{~d}$ & $1.197 \pm 0.036 \mathrm{c}$ & $1.212 \pm 0.073 \mathrm{c}$ & $1.099 \pm 0.027 \mathrm{c}$ & $1.211 \pm 0.089 \mathrm{~d}$ & $1.354 \pm 0.064 \mathrm{~d}$ \\
\hline GF & $0.773 \pm 0.022 \mathrm{c}$ & $1.249 \pm 0.031 \mathrm{~b}$ & $1.304 \pm 0.022 \mathrm{~b}$ & $1.261 \pm 0.071 \mathrm{~b}$ & $1.643 \pm 0.021 \mathrm{c}$ & $1.709 \pm 0.065 \mathrm{c}$ \\
Gf $+1 \mathrm{P}$ & $0.868 \pm 0.037 \mathrm{~b}$ & $1.288 \pm 0.040 \mathrm{~b}$ & $1.323 \pm 0.052 \mathrm{~b}$ & $1.269 \pm 0.089 \mathrm{~b}$ & $1.740 \pm 0.022 \mathrm{~b}$ & $1.823 \pm 0.027 \mathrm{~b}$ \\
Gf+2P & $1.129 \pm 0.031 \mathrm{a}$ & $1.396 \pm 0.026 \mathrm{a}$ & $1.436 \pm 0.036 \mathrm{a}$ & $1.396 \pm 0.102 \mathrm{a}$ & $1.826 \pm 0.019 \mathrm{ab}$ & $1.958 \pm 0.045 \mathrm{a}$ \\
Gf $+3 \mathrm{P}$ & $1.168 \pm 0.027 \mathrm{a}$ & $1.425 \pm 0.020 \mathrm{a}$ & $1.447 \pm 0.051 \mathrm{a}$ & $1.461 \pm 0.042 \mathrm{a}$ & $1.879 \pm 0.085 \mathrm{a}$ & $1.971 \pm 0.064 \mathrm{a}$ \\
\hline
\end{tabular}

mycorrhizal Catharanthus plants at all levels of phosphate. Increase in growth parameters due to mycorrhizal inoculation has been reported earlier in other medicinal plants (Earanna et al., 2002; Sena and Das, 1998). Similar results were obtained by Karthikeyan et al. (2008) in Catharanthus roseus inoculated with Glomus mosseae. Similar report was presented by Matsubara and Sakurai (2000) who also reported that plant production was highly variable with or without mycorrhiza. After 60, 90 and 120 days of AM inoculation, fresh weight and dry weight in mycorrhizal Catharanthus plants at all three levels of phosphate was found to be significantly higher as compared to non mycorrhizal Catharanthus plants. This may be due to the formation of external mycelium around the roots by VAM fungi and the increase in photosynthetic rate. Increase in plant biomass because of AM fungal inoculation has been reported in other medicinal plants like Palmarosa (Gupta and Janardhanan, 1991) and Coleus forskholii (Boby and Bagyaraj, 2003).

As shown in Fig. 1, the percentage of AM colonization was found to be higher at zero and all three phosphate levels after 60,90 and 120 days of AM inoculation, but decreased at third phosphate level after 120 days of AM inoculation. No AM colonization was observed in control plants. This result is in accordance with earlier studies which reported an inhibitory effect of $\mathrm{P}$ on $\mathrm{AM}$ colonization of roots of barley (Khaliq and Sanders, 2000), wheat (Mohammad et al., 2004), and maize (Ozcan and Taban, 2000).

As shown in Fig. 2, total chlorophyll content of leaves showed significant increase in AM inoculated Catharanthus at all three different levels of phosphate after 60, 90 and 120 days of AM inoculation as compared to non AM Catharanthus plants. The increase in total chlorophyll content in inoculated plants may be due to increased uptake of phosphorus, which will increase the photosynthetic activity of Catharanthus roseus plants and ultimately the chlorophyll content. The present results are in agreement with several authors who found increased chlorophyll content in mycorrhizal inoculated plants as compared to non inoculated plants (Allen et al., 1981; Morte et al., 2000;
Mathur and Vyas, 2000). The mutuality of symbiotic fungi stimulated the production of more leaf chlorophyll that consequently may lead to an increase in photosynthetic potential of inoculated plants and hence enhanced growth (Ekanayake et al., 2004).

As shown in Tab. 3, the activities of phosphatase enzymes (acid phosphatase, alkaline phosphatase) were found to be significantly higher in mycorrhizal treated Catharanthus plants as compared to non inoculated $\mathrm{Ca}$ tharanthus plants at all levels of phosphate after 60, 90 and 120 days of AM inoculation. Higher activity of acid phosphatase and alkaline phosphatase were found at $G f+2 p$ and $G f+3 p$ levels. The present results are in agreement with several authors who also observed increased activity of acid phosphatase and alkaline phosphatase in mycorrhizal roots as compared to non mycorrhizal roots. Fries et al. (1998) observed that acid phosphatase and alkaline phosphatase activities in maize roots were closely correlated to levels of AMF colonization of roots. Selvaraj (1998) found that due to inoculation of AM fungi, G. fasciculatum, acid phosphatase activity increased in leaves and roots of $P$. juliflora. Higher uptake of phosphorus in mycorrhizal Catharanthus plants may be due to the increased level of phosphatase enzymes which ultimately resulted in enhanced growth response of Catharanthus roseus. Ezawa $e t$ al. (2001) suggested that ALP in colonized root played an

Tab. 4. Total phosphate content of Catharanthus roseus $\mathrm{L}$. shoot after 60,90 and 120 days of AM inoculation under three different phosphate conditions

\begin{tabular}{cccc}
\hline \multicolumn{4}{c}{ Total Phosphate content mg/g of dry weight } \\
\hline Treatments & 60 days & 90 days & 120 days \\
\hline C & $0.716 \pm 0.080 \mathrm{e}$ & $1.165 \pm 0.068 \mathrm{e}$ & $1.437 \pm 0.044 \mathrm{e}$ \\
C+1P & $1.011 \pm 0.093 \mathrm{~d}$ & $1.949 \pm 0.149 \mathrm{~d}$ & $2.091 \pm 0.238 \mathrm{~d}$ \\
C+2P & $1.110 \pm 0.158 \mathrm{~d}$ & $2.208 \pm 0.246 \mathrm{~cd}$ & $2.404 \pm 0.241 \mathrm{~cd}$ \\
C+3P & $1.440 \pm 0.087 \mathrm{~cd}$ & $2.386 \pm 0.191 \mathrm{bc}$ & $2.497 \pm 0.168 \mathrm{c}$ \\
\hline Gf & $1.250 \pm 0.141 \mathrm{bc}$ & $1.638 \pm 0.077 \mathrm{~b}$ & $1.849 \pm 0.239 \mathrm{bc}$ \\
Gf $+1 \mathrm{p}$ & $1.659 \pm 0.148 \mathrm{ab}$ & $2.364 \pm 0.247 \mathrm{~b}$ & $2.898 \pm 0.162 \mathrm{ab}$ \\
Gf $+2 \mathrm{p}$ & $1.784 \pm 0.149 \mathrm{a}$ & $2.545 \pm 0.122 \mathrm{ab}$ & $3.061 \pm 0.288 \mathrm{a}$ \\
Gf $+3 \mathrm{p}$ & $1.914 \pm 0.302 \mathrm{a}$ & $2.777 \pm 0.257 \mathrm{a}$ & $3.067 \pm 0.359 \mathrm{a}$ \\
\hline
\end{tabular}




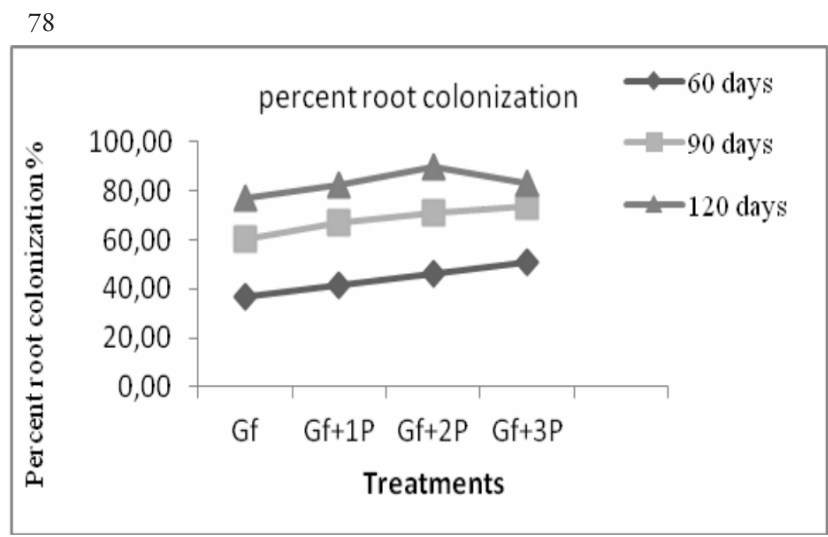

Fig. 1. The percentage of AM colonization in Catharanthus roseus L. after 60, 90 and 120 days of AM inoculation

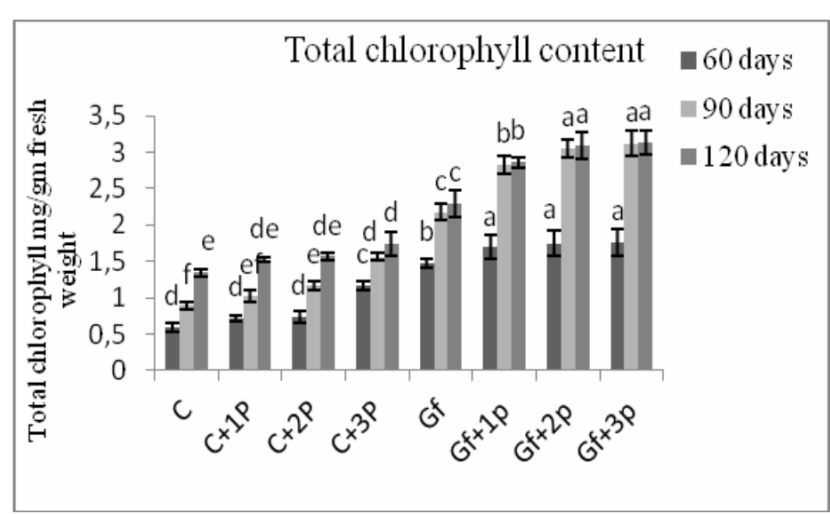

Fig. 2. Total chlorophyll content in Catharanthus roseus L. after 60, 90 and 120 days of AM inoculation

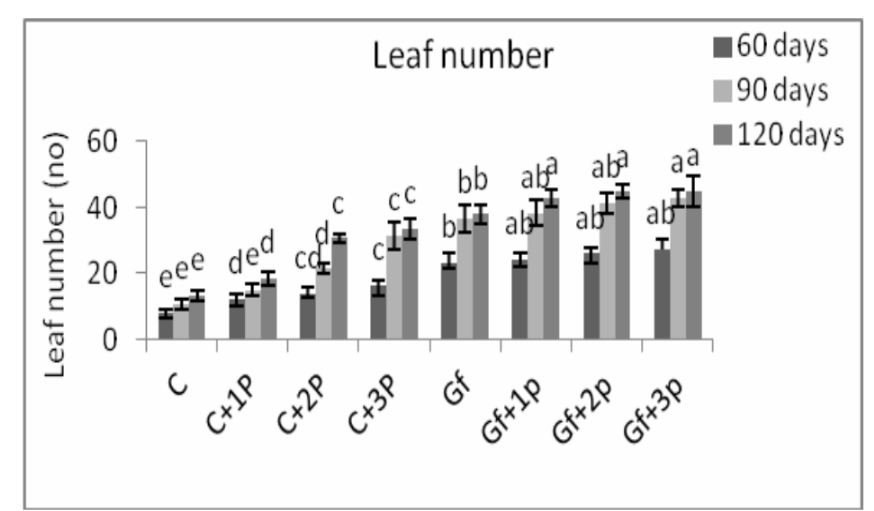

Fig. 3. Number of leaves in Catharanthus roseus inoculated with Glomus fasciculatum after 60,90 and 120 days of AM inoculation

important role in polyP degradation and thus the release of inorganic phosphate $(\mathrm{Pi})$ from arbuscules to root cells. Phosphorus translocated from external hyphae which is normally present in the form of polyphosphate can be hydrolysed by alkaline phosphatase.

The major role of AM fungi is phosphate uptake, because it encodes a phosphate transporter gene. In the present investigation, AM inoculated Catharanthus contained significantly higher total phosphate content in their leaves as compared to non AM Catharanthus at all levels of phosphate after 60, 90 and 120 days of AM inoculation (Tab. 4). The results of the present study coincide with the reported findings of Jackobsen et al. (1992) who have reported that the fungal hyphae growing beyond the rhizospheric soil increase the absorptive surface area of the root, which result in a greater efficiency of nutrient absorption, especially slowly diffusing mineral ions like phosphorus (Kothari et al., 1991; Li et al., 1991). The least uptake of phosphorus was observed in uninoculated control plants. Transport of P into host plants and its release to root cells is an important function of AMF (Ryan et al., 2007; Smith et al., 2001). Increased P absorption is usually attributed to increased surface area and increased soil exploration by the root-AMF association (Miyasaka and Hobte, 2001)

\section{Conclusions}

This work clearly indicates the beneficial effects of AM fungi Glomus fasciculatum on the growth and biomass of economically important plant parts (shoot, root) which are often the harvest products in medicinal plants specifically Catharanthus roseus. Moreover numbers of days taken for first flowering were also reduced due to inoculation of Glomus fasciculatum and application of $100 \mathrm{mg}$ $\mathrm{K}_{2} \mathrm{HPO}_{4} \mathrm{~kg}^{-1}$ was equally as good as $150 \mathrm{mg} \mathrm{K} \mathrm{HPO}_{4} \mathrm{~kg}^{-1}$ of soil. This study shows that the application AM fungi controls growth and development of Catharanthus roseus to a large extent and inorganic fertilizer (Phosphate) alone is not suitable for Catharanthus roseus cultivation.

\section{References}

Allen MF, Smith WK, Moore TS, Christensen M (1981). Comparative water relations and photosynthesis of mycorrhizal and non mycorrhizal Bouteloua gracilis H.B.K. Lag ex Steud. New Phytol 88:683-643.

Audet P, Charest C (2007). Dynamics of arbuscular mycorrhizal symbiosis in heavy metal phytoremediation: meta-analytical and conceptual perspectives. Environ Pollut 147:609-614. 
Arnon DJ (1949). Copper enzymes in isolated chloroplasts. J Plant Cell Physiol 4:29-30.

Boby VU, Bagyaraj DJ (2003). Biological control of root rot of Coleus forskholii Briq. using microbial inoculants. World J Microbiol Biotechn 19:175-180.

Earanna N, Tanuja BP, Bagyaraj DJ, Suresh CK (2002). Vesicular arbuscular mycorrhizal selection for increasing the growth of Rauvolfia tetraphylla. J Med Aromatic Plant Sci 24:695697

Ekanayake IJ, Oyetunji OJ, Osonubi O, Lyasse O (2004). The effects of arbuscular mycorrhizal fungi and water stress on leaf chlorophyll production of cassava (Manihot escullenta Crantz). Food, Agric Environ 2:190-195.

Ezawa T, Smith SE, Smith FA (2001). Differentiation of polyphosphate metabolism between the extra-and intraradical hyphae of arbuscular mycorrhizal fungi. New Phytol 149:555-563.

Fiske CH, Subbarao Y (1925). The colorimetric determination of phosphorus. J Biol Chem 66:375-400.

FriesLLM,PacovskyRS,SafirGR,KaminskiJ(1998). Phosphorus effect on phosphatase activity in endomycorrhizal maize. Physiol Plant 103:152-171.

Gill TS, Singh RS, Kaur J (2002). Comparision of four arbuscular mycorrhizal fungi for root colonization, spore population and plant growth responses in chickpea. Indian Phytopath 55:(2)210-212.

Giovannetti M, Mosse B (1980). An evaluation of techniques for measuring vesicular arbuscular mycorrhizal infection in roots. New Phytol 133:45-57.

Gupta ML, Janardhanan KK (1991). Mycorrhizzal association of Glomus aggregatum with Palmarosa enhances growth and biomass. Plant Soil 131:261-263.

Jackobsen I, Abbott LK, Robson AD (1992). External hyphae of vesicular-arbuscular mycorrhizal fungi associated with Trifolium subterraneum L. I. Spread of hyphae and phosphorus inflow into roots. New Phytol 120:371-380.

Karthikeyan B, Jaleel CA, ChangxingZ, Joe MM, Srimannarayan J, Deiveekasundaram M (2008). The effect of AM fungi and phosphorous level on the biomass yield and ajmalicine production in Catharanthus roseus. EurAsia J Bio Sci 2(3):26-33.

Khaliq A, Sanders FE (2000). Effects of vesicular-arbuscular mycorrhizal inoculation on the yield and phosphorus uptake of field-grown barley. Soil Biol Biochem 32:1691-1696.

Koide RT, Mosse B (2004). A history of research on arbuscular mycorrhiza. Mycorrhiza 14:145-163.

Kothari SK, Marschner H, Romheld V (1991). Contribution of the VAM hyphae in acquisition of phosphorus and zinc by maize grown in a calcareous soil. Plant Soil 131:177-185.

Li XL, George E, Marschner H (1991). Extension of the phosphorus depletion zone in VAM white clover in a calcareous soil. Plant Soil 136:41-48.

Lowry OH, Roberts NR, Mei-Ling WS, Crawford EJ (1954). The quantitative histochemistry of brain II. Enzyme measurements. J Biol Chem 207:19-37.

Mathur N, Vyas A (2000). Influence of arbuscular mycorrhiza on biomass production, nutrient uptake and mycorrhizal changes in Ziziphus mauritiana Lan. Under water stress. J Arid Environ 45:191-195.

Matsubara Y, Sakurai S (2000). Effect of arbuscular mycorrhizal fungus inoculation on growth of Sandersonia. J Soc High Technol Agric 12:47-52.

Miller RM, Jarstfer AG, Pillai JK (1987). Biomass allocation in an Agropyron smithi - Glomus symbiosis. Am J Bot 74:114122.

Miyasaka C, Hobte M (2001). Plant mechanisms and mycorrhizal symbiosis to increase phosphorus uptake efficiency. Commun. Soil Sci Plant Anal 32:1101-1147.

Mohammad A, Mitra B, Khan AG (2004). Effects of shearedroot inoculum of Glomus intraradices on wheat grown at different phosphorus levels in the field. Agricult Ecosyst Environ 103:245-249.

Morte A, Lovisola C, Schubert A (2000). Effect of drought stress on growth and water relations of the mycorrhizal association Helianthemum almeriense Tefezia clavery. Mycorrhiza 10(3):115-119.

Ozcan H, Taban S (2000). Effects of VA-mycorrhiza on growth and phosphorus, zinc, iron, copper and manganese concentrations of maize grown in acid and alkaline soils. Turkish J Agricult Forest 24:629-635.

Phillips JM, Hayman DS (1970). Improved procedures for clearing roots and staining parasitic and vesicular arbuscular mycorrhizal fungi for rapid assessment of colonization. Trans Br Mycol Soc 55:158-160.

Podeszfinski C, Dalpe' Y, Charest C (2002). In situ turf grass establishment. Responses to arbuscular mycorrhizae and fertilization. J Sustain Agric 20:57-74.

Ryan MH, Mc Cully, ME, Huang CX (2007). Relative amounts of soluble and insoluble forms of phosphorus and other elements in intraradical hyphae and arbuscules of arbuscular mycorrhizas. Funct Plant Biol 34:457-464.

Selvaraj T (1998). Studies on mycorrhizal and rhizobial symbioses on tolerance of tannery effluent treated Prosopis juliflora, Ph.D. Thesis, University of Madras, Chennai, India, p. 209.

Sena MK, Das PK (1998). Influence of microbial inoculants on quality of turmeric. Indian Cocoa, Areca Nut Spices J 21:31-33.

Smith SE, Read DJ (1997). Mineral nutrition, heavy metal accumulation and water relations in VA mycorrhizal plants Mycorrhizal Symbiosis, $2^{\text {nd }}$ Ed., Academic Press, San Diego, CA, p. 126-160.

Smith SE, Dickson S, Smith FA (2001). Nutrient transfer in arbuscular mycorrhizas: How are fungal and plant processes integrated? Funct Plant Biol 28:683-694.

Van der Heijden F, Jacobs R, Snoeijer DI, Hallard D, Verpoorte R (2004). The Catharanthus alkaloids: Pharmacognosy and biotechnology. Curr Med Chem 11:607-628. 